items may provide a unit of frequency, but the occurrence of high frequency items when the subject attempts to recall the list may also do so. Hence, the subject would not be able to discriminate which items were and were not on the list, and although he makes some high frequency intrusions, his desire to be accurate means he doesn't produce as many items as he might.

\section{REFERENCES}

Brand, H. A study of the temporal changes in the organization of retention. Journal of General Psychology, 1956, 54, 243-254.
Brand, H., \& Woods, P. J. The organization of the retention of verbal material. Journal of General Psychology, 1958, 58, 55-68.

Cofer, C. N. Does conceptual organization influence the amount retained in immediate free recall. In B. Kleinmuntz (Ed.) Concepts and the structure of memory. New York: John Wiley \& Sons, 1967.

Cofer, C. N., Bruce, D. R., \& Reicher, G. M. Clustering in free recall as a function of certain methodological variations. Journal of Experimental Psy chology, 1966, 71, 858-866.

Cohen, B. H., Bousfield, G. A., \& Whitmarsh, G. A. Cultural norms for verbal items in 43 categories. Technical Report No. 22, 1947, University of Connecticut, Contract Nonr 631(00), Office of Naval Reserach.

Bulletin of the Psychonomic Society 1975, Vol. 5 (2), 129-131

\title{
The relative proximity principle and the postreinforcement pause
}

\author{
RICHARD L. SHULL and AARON J. BROWNSTEIN \\ University of North Carolina, Greensboro, North Carolina 27412
}

\begin{abstract}
According to the relative proximity principle, a response measure should vary monotonically with the relative amount of time elapsed in an interreinforcement interval. Average response rate on fixed-interval schedules does increase monotonically with relative time, but response rate is nonmonotonically related to relative elapsed time on conj FT FR1 schedules. The present paper shows that certain characteristics of the postreinforcement pause distribution are consistent with the relative proximity principle on both fixed-interval and conjunctive schedules: The probability of terminating the postreinforcement pause, given the opportunity, increases monotonically with relative time in the interreinforcement interval on both types of schedules. Thus, the control of postreinforcement pause duration by relative time in an interreinforcement interval seems to hold over a wider range of conditions than does the control over average response rate by relative proximity.
\end{abstract}

On all schedules of reinforcement reinforcers are distributed in time. The time between successive reinforcers is the interreinforcement interval. According to the relative proximity principle (Jenkins, 1970; Staddon, 1972; see also Catania \& Reynolds, 1968; Dews, 1969), the measure of the reinforced response should vary monotonically with elapsed time in the interreinforcement interval. The "relative" indicates that the response measure is more predictable from the elapsed time expressed as a proportion of the interreinforcement interval than from elapsed time expressed in absolute time units without regard to the interreinforcement interval.

The pattern of responding on fixed-interval (FI) schedules is consistent with the relative proximity principle. Average response rate is lowest at the beginning of the interval and highest at the end.

Appearing on the surface inconsistent with the relative proximity principle is the response pattern produced by a schedule having some features in common with FI schedule: the conjunctive fixed-time, fixed-ratio

This research was supported by Grant NIMH (MH21368-01). Reprints may be obtained from $\mathbf{R}$. L. Shull, Department of Psychology, University of North Carolina at Greensboro, Greensboro, North Carolina 27412 one schedule (conj FT FR 1). On FI schedules, reinforcement depends on a response after a fixed amount of time has elapsed. On a conj FT FR 1 schedule reinforcement also depends on a response and an interval of time. But, in contrast with the FI schedule, the order does not matter. Thus, the required response can occur at any time during the interreinforcement interval on the conjunctive schedule. The conj FT FR 1 schedule often produces a pause-respond-pause response pattern so that the highest response rate occurs at the middle of the interreinforcement interval instead of at the end (Morgan, 1970; Shull, 1970, 1971b; Staddon \& Frank, 1974; Zeiler, 1974; see also Barrett, 1974). The relative proximity principle has difficulty accounting for the response rates being higher at intermediate relative proximities than at later relative proximities (see Staddon, 1972, especially Pp. 242-245).

Perhaps the problem is not with the relative proximity principle but rather with average response rate as the dependent measure. If so, it might be advantageous to consider alternative response measures. One alternative is to describe responding on these schedules as a postreinforcement pause and a terminal period. Duration, or latency measures make the most sense with this description. One such measure is the latency of the 


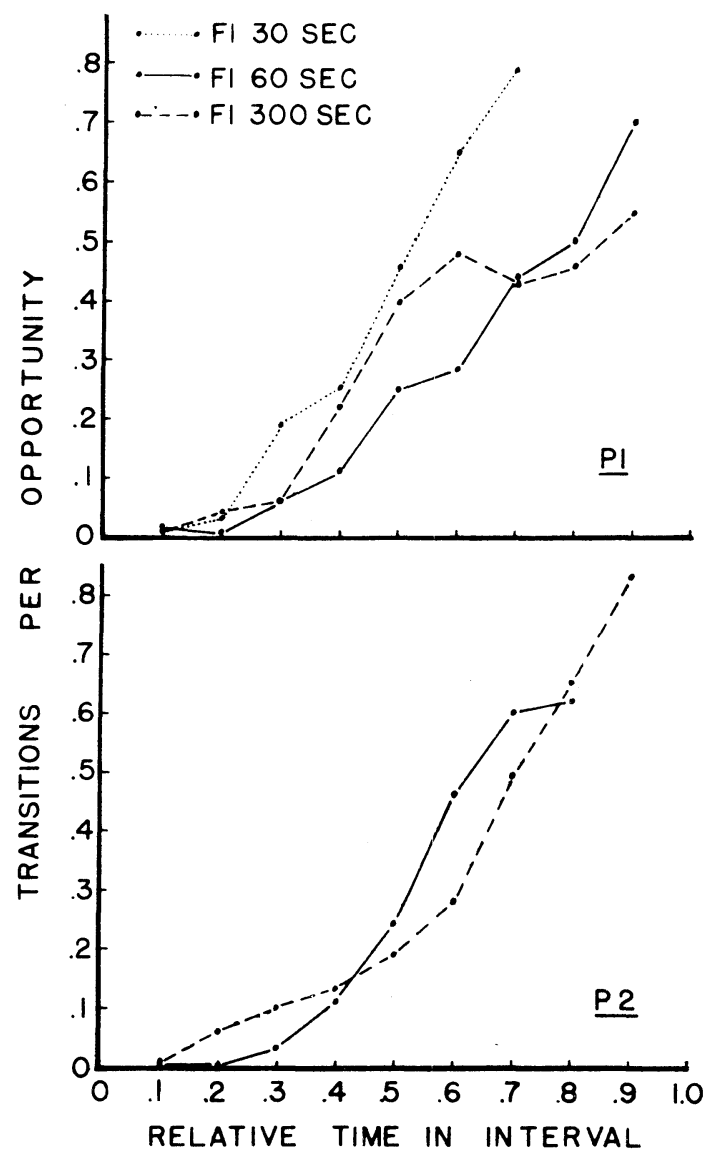

Figure 1. Transitions per opportunity plotted over relative time in the fixed-interval schedule. Points are plotted above the upper value of the time band. Transitions per opportunity values were determined by dividing the number of transitions that occurred in a time band by the number of transitions in that and all longer time bands. Each panel contains the data for a single pigeon given extensive training on each of the fixed-interval schedule durations indicated (see Shull, 1971a). The reinforcer was grain. Each function was derived from a sample of $\mathbf{3 0 0}$ latencies (5 consecutive sessions with 60 intervals per session). Data are not presented for bands containing fewer than 20 opportunities.

transition between the pause and the terminal period (i.e., the duration of the postreinforcement pause).

There is evidence that the transition latency is systematically related to relative proximity. With FI schedules and conj FT FR 1 schedules the average transition latency is a linearly increasing function of the interreinforcement interval. This relation holds for rats and pigeons (Dukich \& Lee, 1973; Morgan, 1970; Schneider, 1969; Schneider \& Neuringer, 1972; Sherman, 1959, Shull, 1970, 1971a; Shull, Guilkey, \& Witty, 1972; Staddon \& Frank, 1974). In other words, the average amount of time that elapses before the transition into the terminal period is a constant proportion of the interreinforcement interval.

While indicating control by relative time, the average transition latency does not indicate how the probability of making the transition changes with relative proximity in an interreinforcement interval. According to the relative proximity principle, the probability of making the transition should increase throughout the interreinforcement interval.

The problem is to determine the probability of making the transition within each successive time band in the interreinforcement interval. It is possible to estimate this probability from a frequency distribution of latencies by dividing the number of transitions in a time band by the number of occasions transitions could have been made in the time band (opportunities). Since a transition can occur in a time band only if a transition has not occurred earlier in the interreinforcement interval, the denominator (opportunities) is the number of latencies in that and all longer time bands. This ratio, here termed transitions per opportunity, is computationally and logically equivalent to Anger's (1956) interresponse time per opportunity statistic (see also McGill, 1963).

The following three figures show how the transitions per opportunity statistic varies with relative time in an interreinforcement interval on FI schedules and on conj FT FR 1 schedules.

Figure 1 shows the relation between transitions per opportunity and relative time in the interval for different FI schedule durations (30-, 60-, and 300-sec). The data are from two pigeons given extensive training on the FI durations indicated in the figure. (The average transition latencies- or mean-postreinforcement pauses-and procedural details have been reported by Shull, 1971a). With few exceptions, the transitions per opportunity statistic increased with relative time in the interreinforcement interval.

Figure 2 also shows transitions per opportunity functions for a pigeon given extensive training on several FI schedule durations. The frequency distributions were reported by Schneider (1969), and the transitions per opportunity values were calculated from the data in his Figure 6. Again, the transitions per opportunity statistic increased with relative time in the interreinforcement interval. In addition to control by relative proximity, there is an effect of absolute FI duration on the slope of the functions: for a given relative proximity the transitions per opportunity value was lower the longer the FI duration. It is unclear why there was a stronger effect of FI duration in the data reported by Schneider (1969) than in the data shown in Figure 1. One of several possibilities is that a difference in the definition of the transition was responsible. For the data in Figure 1 the transition was defined as the first response in each interval; Schneider defined the transition as the point of maximum acceleration of response rate in an interreinforcement interval. Whatever the reason for the difference, the inconsistent effect of absolute interval duration is much less significant than the consistent finding that the transitions per opportunity functions increased throughout the interreinforcement interval on 


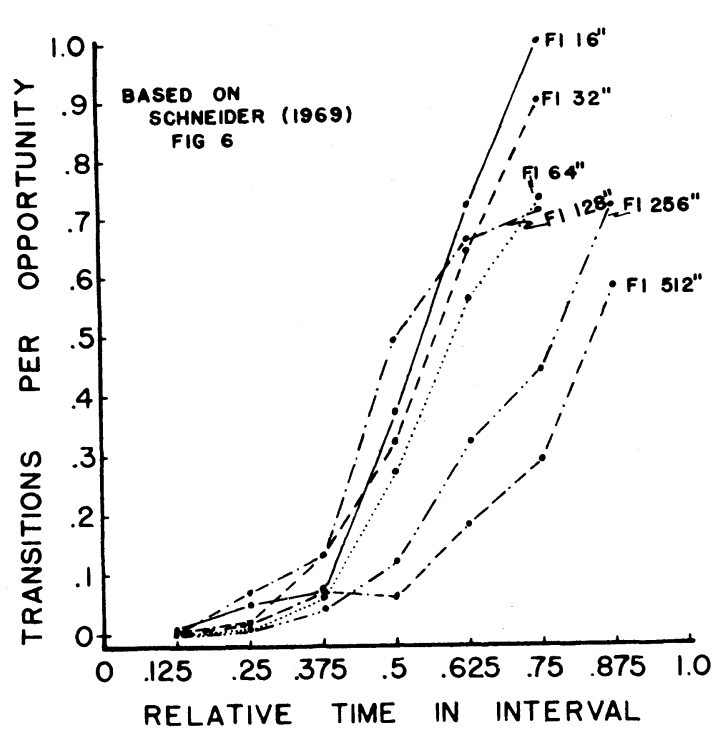

Figure 2. Transitions per opportunity plotted over relative time in the fixed-interval schedule. The data are from a single pigeon given extensive training on each of the fixed-interval schedule durations indicated. The reinforcer was grain. Each function was derived from data reported by Schneider (1969, Figure 6). Data are not presented for bands containing fewer than $10 \%$ of the total sample as opportunities.

\section{the FI schedules.}

For FI schedules, then, both average response rate and transitions per opportunity increase throughout the interreinforcement interval. As mentioned above, however, average response rate is nonmonotonically related to relative proximity on conj FT FR 1 schedules. Figure 3 shows the transitions per opportunity function for each of two pigeons trained on a conj FT 300-sec FR 1 schedule. (The procedural details and average latency values have been reported previously by Shull, 1970.) Since the highest response rates occurred near the middle of the interreinforcement interval, it is particularly significant that the transitions per opportunity statistic increased throughout the interreinforcement interval. Thus, the transitions per opportunity statistic varied in a way consistent with the relative proximity principle on the conjunctive schedule even when response rate did not.

These data suggest two related points: First, transition latencies (postreinforcement pauses) are controlled by relative proximity, but appropriate transformations of the latency distribution are necessary to reveal that control. Secondly, the control of transition latency by relative proximity appears to hold over a wider range of conditions than does the control of response rate by relative proximity.

\section{REFERENCES}

Anger, D. The dependence of interresponse times upon the relative reinforcement of different interresponse times. Journal of Experimental Psychology, 1956, 52, 145-161.

Barrett, J. E. Conjunctive schedules of reinforcement I:

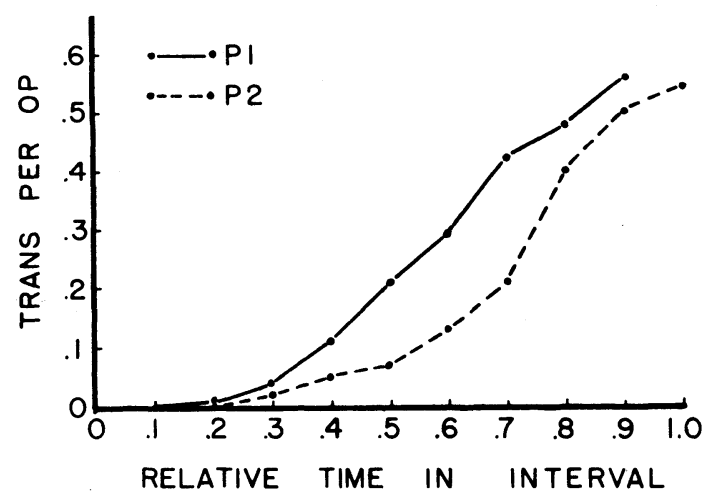

Figure 3. Transitions per opportunity plotted over relative time in the conj FT 300-sec FR 1 schedule. The data are from two pigeons trained on the conjunctive schedule for grain reinforcement (Shull, 1970). Each function was derived from a sample of 300 latencies (5 consecutive sessions with 60 intervals per session). Data are not presented for bands containing fewer than 20 opportunities.

Rate-dependent effects of pentobarbital and d-amphetamine. Journal of the Experimental Analysis of Behavior, 1974 (in press).

Catania, A. C., \& Reynolds, G. S. A quantitative analysis of the responding maintained by interval schedules of reinforcement. Journal of the Experimental Analysis of Behavior, 1968, 11, 327-383.

Dews, P. B. Studies of responding under fixed-interval schedules of reinforcement: The effects on the pattern of responding of changes in requirements at reinforcement. Journal of the Experimental Analysis of Behavior, 1969,12, 191-199.

Dukich, T. D., \& Lee, A. E. A comparison of measures of responding under fixed-interval schedules. Journal of the Experimental Analysis of Behavior, 1973, 20, 281-290.

Jenkins, H. M. Sequential organization in schedules of reinforcement. In W. N. Schoenfeld (Ed.), The theory of reinforcement schedules. New York: Appleton-Century-Crofts, 1970, Pp. 63-109.

McGill, W. J. Stochastic latency mechanisms. In R. D. Luce, R. R. Bush, \& E. Galanter (Eds.), Handbook of mathematical psychology. Vol. 1, New York: Wiley, 1963, Pp. 309-360.

Morgan, M. J. Fixed interval schedules and delay of reinforcement. Quarterly Journal of Experimental Psychology, 1970, 22, 663-673.

Schneider, B. A. A two-state analysis of fixed-interval responding in the pigeon. Journal of the Experimental Analysis of Behavior, 1969, 12, 677-687.

Schneider, B. A., \& Neuringer, A. J. Responding under discrete-trial fixed-interval schedules of reinforcement. Journal of the Experimental Analysis of Behavior, 1972, 18, 187-199.

Sherman, J. G. The temporal distribution of responses on fixed interval schedules. Unpublished doctoral dissertation. Columbia University, 1959.

Shull, $R$. L. The response-reinforcement dependency in fixed-interval schedules of reinforcement. Journal of the Experimental Analysis of Behavior, 1970, 14, 55-60.

Shull, R. L. Sequential patterns in post-reinforcement pauses on fixed-interval schedules of food. Journal of the Experimental Analysis of Behavior, 1971, 15, 221-231. (a)

Shull, R. L. Postreinforcement pause duration on fixed-interval and fixed-time schedules of food reinforcement. Psychonomic Science, 1971, 23, 77-78. (b)

Shull, R. L., Guilkey, M., \& Witty, W. Changing the response unit from a single peck to a fixed number of pecks in fixed-interval schedules. Journal of the Experimental Analysis of Behavior, 1972, 17, 193-200.

Staddon, J. E. R. Temporal control and the theory of reinforcement schedules. In R. M. Gilbert \& J. R. Millenson (Eds.), Reinforcement: Behavioral analyses. New York: Academic Press, 1972, Pp. 209-262.

Staddon, J. E. R., \& Frank. J. A. The role of the peck-food contingency on fixed-interval schedules. Journal of the Experimental Analysis of Behavior, 1974 (in press).

Zeiler, M. D. Schedules of reinforcement: The controlling variables. In W. K. Honig \& J. E. R. Staddon (Eds.), Operant behavior. Vol. 2, 1974 (in press).

(Received for publication October 7, 1974.) 